\title{
Author Correction: Microbial spatial footprint as a driver of soil carbon stabilization
}

\author{
A.N. Kravchenko ${ }^{1,2,3}$, A.K. Guber ${ }^{1,2}$, B.S. Razavi ${ }^{4}$, J. Koestel ${ }^{5}$, M.Y. Quigley (1) ${ }^{1}$, G.P. Robertson (D) ${ }^{1,2,6} \&$ \\ Y. Kuzyakov $3,7,8$
}

Correction to: Nature Communications https://doi.org/10.1038/s41467-019-11057-4, published online 16 July 2019.

The original version of this Article omitted the following from the end of the Acknowledgements: 'We gratefully acknowledge the German Research Foundation (DFG) for supporting the project: RA3062/3-1.' This has now been corrected in both the PDF and HTML versions of the Article.

Published online: 05 September 2019

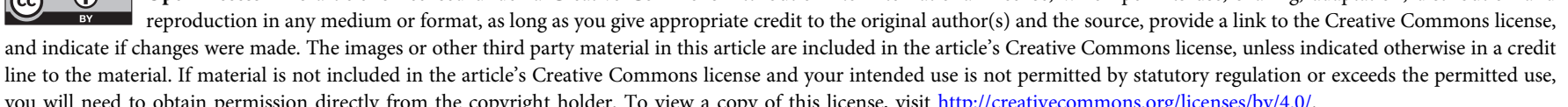
you will need to obtain permission directly from the copyright holder. To view a copy of this license, visit http://creativecommons.org/licenses/by/4.0/.

(C) The Author(s) 2019

\footnotetext{
${ }^{1}$ Department of Plant, Soil and Microbial Sciences, Michigan State University, East Lansing, MI 48824, USA. ${ }^{2}$ DOE Great Lakes Bioenergy Research Center, Michigan State University, East Lansing, MI, USA. ${ }^{3}$ Department of Agricultural Soil Science, University of Göttingen, Göttingen, Germany. ${ }^{4}$ Department of Soil and Plant Microbiome, Institute of Phytopathology, Christian-Albrecht-University of Kiel, Kiel, Germany. ${ }^{5}$ Swedish University of Agricultural Sciences, Uppsala, Sweden. ${ }^{6}$ W. K. Kellogg Biological Station, Michigan State University, Hickory Corners, MI 49060, USA. ${ }^{7}$ Institute of Physicochemical and Biological Problems in Soil Science, 142290 Pushchino, Russia. ${ }^{8}$ RUDN University, Moscow, Russia. Correspondence and requests for materials should be addressed to A.N.K. (email: kravche1@msu.edu)
} 